\title{
A Probabilistic Model of the Unidirectional Tensile Strength of Fiber-Reinforced Polymers for Structural Design
}

\author{
Jianqing Zhang $\mathbb{D}^{1},{ }^{1}$ Ruikun Zhang $\mathbb{D}^{1},{ }^{1}$ and Yihua Zeng $\mathbb{D}^{2}$ \\ ${ }^{1}$ Jiangsu Huaning Engineering Consulting Company Limited, Southeast University, Nanjing 210018, China \\ ${ }^{2}$ School of Civil Engineering, Southeast University, Nanjing 211189, China \\ Correspondence should be addressed to Yihua Zeng; yihua.zeng@foxmail.com
}

Received 4 October 2021; Accepted 10 December 2021; Published 24 December 2021

Academic Editor: Dongsheng Huang

Copyright ( $(2021$ Jianqing Zhang et al. This is an open access article distributed under the Creative Commons Attribution License, which permits unrestricted use, distribution, and reproduction in any medium, provided the original work is properly cited.

In this paper, a statistical analysis of the tensile strength of FRP composites is conducted. A relatively large experimental database including 58 datasets is first constructed, and the Normal, Lognormal, and Weibull distributions are fitted to the data using a tailsensitive Anderson-Darling statistic as the measure of goodness of fit. Fitting results show that the Normal, Lognormal, and Weibull distributions can be used to model the tensile strength of FRP composites. Then, the characteristic value for the tensile strength of FRP composites at a fixed percentile is analyzed. It is found that the Weibull distribution results in a higher safety margin in comparison to either the Normal or the Lognormal distribution. When the experimental justification, the theoretical justification, as well as the design conservativeness are taken into consideration, the Weibull distribution is the most recommended distribution to model the tensile strength of FRP composites. Furthermore, a probabilistic model considering the statistical uncertainty for the tensile strength for FRP composites is proposed. It is believed that the statistical uncertainty can be modeled as a reduction factor, and the recommended value of such factor for engineering design practices is provided based on regression analysis.

\section{Introduction}

Fiber-reinforced polymers (FRPs) have been intensively used in the repair and retrofitting of existing structures during the last few decades; thus, many research efforts have been made towards increasing the understanding of FRP itself and the interaction between FRP and existing structures. To design highly reliable FRP-related structural systems, quantification of the uncertainty in the material properties of FRP composites is necessary and crucial. As is known, the tensile strength of FRP composites is one of the most important properties that can affect the structural response, as observed in many experiments. Therefore, quantification of the uncertainties in the tensile strength of FRP composites is essential for the development of robust designs that meet target reliability levels.

A variety of probabilistic distributions, e.g., the Normal, Lognormal, and Weibull distributions, is usually used to model the tensile properties of FRP composites. Generally, a set of nominally identical experiments is conducted using relevant ASTM standards or guidelines (e.g., The Composite Materials Handbook MIL-HDBK-17-1F [1]), and then, a distribution selection is carried out using hypothesis testing methods such as the chi-square, Kolmogorov-Smirnov, or Anderson-Darling tests (e.g., Atadero et al. [2] and Zureick et al. [3]). By following this methodology, several researchers have studied the uncertainties of the tensile behavior of FRP composites under different conditions. For example, Barbero et al. [4] presented generalized formulae to describe the behavior of the Weibull estimators for composites and proposed expressions to describe the A-basis and B-basis material properties for design practices.

In the work of Alqam et al. [5], the two-parameter and three-parameter Weibull distributions were compared to model the strength and stiffness properties of pultruded carbon FRP (CFRP) composites from 26 mechanical property datasets. The modified moment method and the maximum likelihood method were used to estimate the 
Weibull parameters, and the Anderson-Darling statistic [6] was used to test the goodness of fit. It was found that in comparison with the two-parameter Weibull distribution, the three-parameter Weibull distribution is slightly better in modeling the strength and stiffness of FRP composites. However, the difference in the fitting results between these two Weibull distributions is marginal. It was found that the design value obtained from the two-parameter Weibull distribution is on average $5 \%$ lower than that obtained from the three-parameter Weibull distribution. In the interest of being conservative, the authors recommended the two-parameter Weibull distribution to model the strength and stiffness properties of FRP composites. Based on this work and others that used the same datasets, Zureick et al. [3] performed a study on the statistical characterization of the mechanical properties of FRP composites. The Normal, Lognormal, and Weibull distributions (the two-parameter Weibull distribution, if not specified, otherwise) were chosen to fit the datasets. It was concluded that the Weibull distribution is not significantly better than either the Normal or the Lognormal distribution. In the work of Zureick et al., the Weibull distribution was still recommended because it is the most commonly used distribution for composite materials due to its intrinsic weakest link hypothesis of failure and the fact that it provides higher safety margins with respect to design values compared to either the Normal or Lognormal distribution.

To investigate the variability of field-manufactured carbon panels for bridge deck rehabilitations, the Normal, Lognormal, Weibull, and Gamma distributions have been adopted to fit datasets for the tensile strength, Young's modulus, and thickness by using the Chi-square test statistics as the indicator of goodness of fit [2]. Observations showed that the Weibull distribution was the best descriptor of tensile strength and that the Lognormal distribution was the best descriptor for Young's modulus. More recently, Gomes et al. [7] performed a probabilistic assessment of 1,368 tensile tests of CFRP specimens. These specimens were precured and produced under the same conditions by the same manufacturer. Statistical analysis with regard to the tensile strength, Young's modulus, and ultimate strain of the tested CFRP laminates was conducted using the Normal and the Weibull distributions. It was concluded that the Weibull distribution can be used to model the tensile strength, Young's modulus, and the ultimate strain for the lower $20^{\text {th }}$ percentile of the sample. In addition, Gohil and Shaikh [8] reported the statistical results of the tensile tests of the glass fiber and a glass-polyester composite. Naresh et al. [9] also presented the experimental results for CFRP, glass FRP (GFRP), and hybrid FRP composites with respect to the tensile strength under different strain rate conditions. In references $[8,9]$, the Weibull distribution was also used to model the tensile strength of FRP composites. From the above references, it is found that the Weibull distribution is the most widely used distribution for modeling the tensile strength of FRP composites. In fact, the Weibull distribution arises from the weakest link hypothesis of failure and has some theoretical justifications to model composite materials [10].
Although many efforts have been carried out for the probabilistic modeling of the tensile strength of FRP composites, there are still numerous aspects that prevent the efficient characterization of the tensile strength of FRP composites for engineering design. This situation is mainly attributed to the lack of the following pieces of fundamental knowledge:

(i) The best-fitted distribution type is not convincing from the perspective of experimental justification. This is mainly because the datasets used for experimental justification in the above-mentioned references are rather limited. For example, in the work of Zureick et al. [3], 5 datasets for characterization of the tensile strength were used. On the one hand, neither the Normal nor the Lognormal distributions can be rejected for any of the 5 datasets; on the other hand, the Weibull distribution was rejected for 2 out of 5 sets ( $40 \%$ rejection). In this situation, it is not convincing that the Weibull distribution should be adopted for the tensile strength of FRP composites. Similarly, the conclusion of Atadero et al. [2] that the Weibull distribution is the best for tensile strength is not sound when only 3 datasets were used.

(ii) The statistical uncertainty due to the parameter estimation from a sample of limited size is not well considered in many situations. For given test data, the $p$-percentile value of the fitted distribution is commonly taken as the nominal design value. However, this nominal design value does not account for the statistical uncertainty of parameter estimation, and this normally results in an overestimate of the material strength. Especially when the Weibull distribution is considered, difficulties arise in the estimation of the statistical uncertainty because the sample distributions and confidence intervals for the estimators are unavailable in closed forms. Therefore, the proposal of a reduction factor accounting for such statistical uncertainty is meaningful and desirable.

The primary objective of this study is to formulate a probabilistic model with respect to the tensile strength of FRP composites for engineering design purposes. To achieve this objective, a relatively large experimental database of CFRP and GFRP composites was first created. Then, the Normal, Lognormal, and Weibull distributions were fitted to all the datasets using the maximum likelihood method, and the tail-sensitive Anderson-Darling statistic was used as the indicator of goodness of fit. The fitting results are discussed to examine the appropriateness of the three distributions from the perspective of experimental justification. Furthermore, the statistical uncertainty arising from random fluctuations in the measurement of each dataset was analyzed, and this uncertainty was quantified by a reduction factor in the proposed design-orientated probabilistic model. 


\section{Statistical Characterization of the Tensile Strength of FRP Composites}

According to The Composite Materials Handbook-MILHDBK-17-1F [1], the Weibull distribution is examined first, and, if not rejected by a statistical hypothesis test, chosen as the distribution for FRP composites. More specifically, the twoparameter rather than the three-parameter Weibull distribution is selected for the first examination. This is due to the observation that the third parameter (location) in the three-parameter Weibull distribution does not significantly improve the characterization results and the fact that the two-parameter Weibull distribution gives reasonable results with good computational efficiency [5]. To be consistent with other aforementioned studies, three commonly used distributions for reliability analysis, i.e., the Normal, Lognormal, and Weibull distributions, were used herein. The probability density function for each is given in equations (1)-(3).

$$
\begin{aligned}
& \text { Normal: } f(x \mid, \sigma)=\frac{1}{\sigma \sqrt{2 \pi}} \exp \left[-\frac{1}{2}\left(\frac{x-\mu}{\sigma}\right)^{2}\right] \text {, } \\
& \sigma>0 ;-\infty<x, \mu<\infty,
\end{aligned}
$$

where $\mu$ and $\sigma$ are the mean and standard deviation of the variable $X$, respectively.

Lognormal : $f(x \mid \mu, \sigma)=\frac{1}{x \sigma \sqrt{2 \pi}} \exp \left[-\frac{1}{2}\left(\frac{\ln x-\mu}{\sigma}\right)^{2}\right]$,

$$
x>0 ; \sigma>0 ;-\infty<\mu<\infty
$$

where $\mu$ and $\sigma$ are, respectively, the mean and the standard deviation of the natural logarithms of the variable $X$.

$$
\begin{array}{r}
\text { Weibull : } f(x \mid \alpha, \beta)=\frac{\beta}{\alpha^{\beta}} x^{\beta-1} \exp \left[-\left(\frac{x}{\alpha}\right)^{\beta}\right], \\
x \geq 0 ; \alpha, \beta>0,
\end{array}
$$

where $\alpha$ and $\beta$ are the shape and scale parameters of the variable $X$, respectively.

2.1. Experimental Database. FRP composites constitute fibers and resin. The tensile strength of FRP composites cannot be easily described and is dependent on many factors. On the one hand, the tensile strength of FRP composites is affected by the type of reinforced fiber (e.g., carbon, glass, aramid, basalt, or natural fibers, or a mixture of different kinds of fibers), the fiber form (e.g., continuous or chopped), the fiber orientation (i.e., unidirectional, bidirectional, or multidirectional), the type of resin (i.e., thermoset and thermoplastic), the manufacturing technology (e.g., pultrusion, filament winding, autoclave, or wet layup processes), and curing conditions; on the other hand, the observed/tested tensile strength of FRP composites is also influenced by the test methods (e.g., tensile test or bending test) and loading rates (e.g., quasistatic or dynamic loading).
Therefore, to characterize the tensile strength of FRP composites, it is necessary to limit the scope of the involved test results. As known, in the application of FRP composites in structural engineering (i.e., mainly strengthening, retrofitting, and rehabilitation), the FRP composite is usually considered as a perfect tensile brittle material. In other words, no matter how the FRP composite is manufactured and cured, it is believed that the load of interest is applied to those continuous fibers along the fiber orientation. The resin and fibers orientated in other directions are not believed to contribute to the tensile strength explicitly. For example, in the load-bearing capacity analysis of a concrete beam externally bonded with bidirectional FRP composites, the tensile strength of the FRP material is deemed to be mainly attributed to the fibers along the strengthening direction.

Consequently, the experimental database in this work can be constructed by collecting the tensile test results of those FRP composites tested with loading along the axial fiber orientation. The tested composites can be in the form of microcomposites, sheets, laminates, plates, and coupons from pultruded thick products such as bridge decks. It is noted that results from tensile tests for a single fiber or fiber bundle/tow are inappropriate because the absence of resin does not make a single fiber or fiber bundle/tow a composite. In this study, only carbon and glass fibers are considered as they are the most frequently used composites in structural engineering. With respect to the test methods, the quasistatic tests are basic options according to test standards such as ASTM D3039 [11] and ISO 527 [12]. The dynamic or impact test is also selected. Although the dynamic tensile strength of a specific type of FRP composite deviates from its quasistatic tensile strength, the tensile strength of the FRP composite under dynamic loading can also be modeled by the same distributions that are used to model the quasistatic tensile strength of the same FRP composite, as indicated by $\mathrm{Ou}$ and Zhu [13].

To set up a relevant large experimental database, the tensile test results of FRP composites reported in published literature (mainly journal articles) during the last decades were reviewed and collected. A total of 58 datasets $(1,171$ samples) are summarized in Table 1 , in which the specimen size (thickness $t_{f}$, width $b_{f}$, and length $l_{f}$ ), test speed, followed standard, and references are listed. The database consists of 31 datasets (391 samples) of GFRP composites and 27 datasets (780 samples) of CFRP composites. For example, a histogram as well as probability distributions fitted by the Normal, Lognormal, and Weibull distributions with respect to datasets 57 and 58 are shown in Figure 1.

Since all the datasets in the experimental database are used to investigate the fitness of the selected distributions in the hypothesis tests and to examine the statistical uncertainties arising from parameter estimations, the sampling error due to measurement shortage should be minimized. Therefore, only those datasets resulting in small estimation errors can be selected. It is well known that the minimum sample size is mainly associated with the variation of the sample and the acceptable estimation error. It is noted that each dataset shown in Table 1 passes the test that the estimation error of the dataset should be smaller than the acceptable level. In this study, the acceptable estimation error is chosen in such a way that the error of the 
TABLE 1: Summary of the experimental database.

\begin{tabular}{|c|c|c|c|c|c|c|c|c|}
\hline \multirow[t]{2}{*}{ Set no. } & \multirow[t]{2}{*}{ Set size } & \multirow[t]{2}{*}{ Material } & \multicolumn{3}{|c|}{$\begin{array}{l}\text { Specimen size } \\
(\mathrm{mm})\end{array}$} & \multirow[t]{2}{*}{ Test speed } & \multirow[t]{2}{*}{ Standard } & \multirow[t]{2}{*}{ Reference } \\
\hline & & & $t_{f}$ & $b_{f}$ & $l_{f}$ & & & \\
\hline 1 & 7 & Glass/epoxy laminate & 1.5 & 12.7 & 25.4 & n.a. & n.a. & Rosen 1964 [14] \\
\hline 2 & 5 & Glass/epoxy laminate & 1.5 & 12.7 & 25.4 & n.a. & n.a. & \\
\hline 3 & 6 & Glass/epoxy laminate & 1.5 & 12.7 & 25.4 & n.a. & n.a. & Zweben 1968 [15] \\
\hline 4 & 13 & Carbon/epoxy laminate & n.a. & n.a. & n.a. & n.a. & n.a. & \\
\hline 5 & 36 & Carbon/epoxy tow & n.a. & n.a. & n.a. & n.a. & n.a. & Bullock 1974 [16] \\
\hline 6 & 29 & Glass/epoxy prepreg & n.a. & 25.4 & 203 & n.a. & n.a. & Sun and Yamada 1978 [17] \\
\hline 7 & 25 & Carbon/epoxy panel coupon & n.a. & 12.7 & 229 & n.a. & D3039 & \\
\hline 8 & 20 & Carbon/epoxy panel coupon & n.a. & 12.7 & 229 & n.a. & D3039 & Whitney and Knight 1980 [18] \\
\hline 9 & 36 & Carbon/epoxy panel coupon & n.a. & 12.7 & 229 & n.a. & D3039 & \\
\hline 10 & 49 & S2-glass/epoxy & n.a. & n.a. & n.a. & n.a. & n.a. & Shimokawa et al. 1989 [19] \\
\hline 11 & 30 & Carbon/epoxy laminate & n.a. & 38 & 300 & n.a. & n.a. & Beyerlein and Phoenix 1990 [20] \\
\hline 12 & 31 & Carbon/epoxy microlaminate & n.a. & n.a. & n.a. & n.a. & n.a. & \\
\hline 13 & 21 & Carbon/epoxy microlaminate & n.a. & n.a. & n.a. & n.a. & n.a. & \\
\hline 14 & 48 & Carbon/epoxy microlaminate & n.a. & n.a. & n.a. & n.a. & n.a. & \\
\hline 15 & 24 & Carbon/epoxy microlaminate & n.a. & n.a. & n.a. & n.a. & n.a. & \\
\hline 16 & 30 & Carbon/epoxy microlaminate & n.a. & n.a. & n.a. & n.a. & n.a. & \\
\hline 17 & 6 & Carbon/epoxy prepreg & 3.4 & 38.2 & 324 & $0.00047 \mathrm{~s}^{-1}$ & D3039 & Lavoie 1997 [21] \\
\hline 18 & 7 & Carbon/epoxy prepreg & 4.5 & 50.9 & 431 & $0.00047 \mathrm{~s}^{-1}$ & D3039 & \\
\hline 19 & 7 & Carbon/epoxy prepreg & 1.1 & 12.7 & 108 & $0.00047 \mathrm{~s}^{-1}$ & D3039 & \\
\hline 20 & 7 & Carbon/epoxy prepreg & 2.2 & 25.5 & 219 & $0.00047 \mathrm{~s}^{-1}$ & D3039 & \\
\hline 21 & 7 & Carbon/epoxy prepreg & 3.4 & 38.2 & 324 & $0.00047 \mathrm{~s}^{-1}$ & D3039 & \\
\hline 22 & 7 & Carbon/epoxy prepreg & 1.1 & 12.7 & 108 & $0.00047 \mathrm{~s}^{-1}$ & D3039 & \\
\hline 23 & 8 & E-glass/epoxy laminate & 1.6 & 100 & 250 & $3 \mathrm{~mm} / \mathrm{min}$ & n.a. & Cattell and Kibble 2001 [22] \\
\hline 24 & 14 & E-glass/epoxy laminate & 1.0 & 100 & 250 & $3 \mathrm{~mm} / \mathrm{min}$ & n.a. & \\
\hline 25 & 20 & Carbon/epoxy laminate & 8.0 & 10 & 60 & $2.64 \mathrm{~mm} / \mathrm{min}$ & D3039 & Ochola 2004 [23] \\
\hline 26 & 20 & Glass/epoxy laminate & 8.0 & 10 & 60 & $2.64 \mathrm{~mm} / \mathrm{min}$ & D3039 & \\
\hline 27 & 19 & Carbon/epoxy sheet & 0.89 & 15 & 206 & $1.33 \mathrm{~mm} / \mathrm{min}$ & D3039 & Birgoren and Husnu Dirikolu 2004 [24] \\
\hline 28 & 6 & E-glass/epoxy & 1.2 & 15 & 250 & $1 \mathrm{~mm} / \mathrm{min}$ & ISO 527 & Makarov et al. 2004 [25] \\
\hline 29 & 5 & E-glass/epoxy & 1.2 & 15 & 250 & $3.8 \mathrm{~s}^{-1}$ & n.a. & \\
\hline 30 & 5 & E-glass/epoxy & 1.2 & 15 & 250 & $22.65 \mathrm{~s}^{-1}$ & n.a. & Makarov et al. 2004 [25] \\
\hline 31 & 5 & E-glass/epoxy & 1.2 & 15 & 250 & $32.34 \mathrm{~s}^{-1}$ & n.a. & \\
\hline 32 & 5 & E-glass/epoxy & 1.2 & 15 & 250 & $39.85 \mathrm{~s}^{-1}$ & n.a. & \\
\hline 33 & 5 & E-glass/epoxy & 1.2 & 15 & 250 & $40.89 \mathrm{~s}^{-1}$ & n.a. & \\
\hline 34 & 30 & E-glass/vinyl ester coupon & 6.4 & 25.4 & 330 & $2.5 \mathrm{~mm} / \mathrm{min}$ & D3039 & Zureick et al. 2006 [3] \\
\hline 35 & 30 & E-glass/vinyl ester coupon & 9.6 & 25.4 & 330 & $2.5 \mathrm{~mm} / \mathrm{min}$ & D3039 & \\
\hline 36 & 24 & E-glass/vinyl ester coupon & 6.4 & 25.4 & 330 & $2.5 \mathrm{~mm} / \mathrm{min}$ & D3039 & \\
\hline 37 & 24 & E-glass/vinyl ester coupon & 6.4 & 25.4 & 330 & $2.5 \mathrm{~mm} / \mathrm{min}$ & D3039 & \\
\hline 38 & 30 & E-glass/vinyl ester coupon & n.a. & n.a. & n.a. & n.a. & n.a. & \\
\hline 39 & 5 & Glass/epoxy laminate & 1.0 & 12.7 & 82.7 & $0.0017 \mathrm{~s}^{-1}$ & n.a. & Shokrieh and Omidi 2009 [26] \\
\hline 40 & 5 & Glass/epoxy laminate & 1.0 & 12.7 & 82.7 & $0.55 \mathrm{~s}^{-1}$ & n.a. & \\
\hline 41 & 5 & Glass/epoxy laminate & 1.0 & 12.7 & 82.7 & $5.6 \mathrm{~s}^{-1}$ & n.a. & \\
\hline 42 & 5 & Glass/epoxy laminate & 1.0 & 12.7 & 83.7 & $46 s^{-1}$ & n.a. & \\
\hline 43 & 5 & Glass/epoxy laminate & 1.0 & 12.7 & 82.7 & $85 s^{-1}$ & n.a. & \\
\hline 44 & 30 & Carbon/epoxy plate & 1.0 & 5.0 & 120 & $0.5 \mathrm{~mm} / \mathrm{min}$ & n.a. & Okabe et al. 2010 [27] \\
\hline 45 & 20 & Carbon/epoxy laminate & 2.0 & 25 & 230 & $2 \mathrm{~mm} / \mathrm{min}$ & GB/T3354 & Wang and yang $2010[28]$ \\
\hline 46 & 20 & Carbon/epoxy laminate & 2.0 & 15 & 175 & $2 \mathrm{~mm} / \mathrm{min}$ & D3039 & Du et al. 2012 [29] \\
\hline 47 & 7 & Glass/polyester panel coupon & 1.0 & 15 & 250 & $2 \mathrm{~mm} / \mathrm{min}$ & D3039 & Gohil and Shaikh 2013 [8] \\
\hline 48 & 60 & Carbon/epoxy panel coupon & 0.8 & 12.5 & 330 & $2 \mathrm{~mm} / \mathrm{min}$ & D3039 & Sasikumar et al. 2015 [30] \\
\hline 49 & 9 & Glass/epoxy laminate & 0.6 & 2.64 & 105 & $120 \mathrm{~s}^{-1}$ & n.a. & Ou and Zhu 2015 [13] \\
\hline 50 & 8 & Glass/epoxy laminate & 0.6 & 2.64 & 105 & $40 s^{-1}$ & n.a. & \\
\hline 51 & 10 & Glass/epoxy laminate & 0.52 & 22 & 105 & $1 / 600 s^{-1}$ & n.a. & Ou et al. 2016 [31] \\
\hline 52 & 9 & Glass/epoxy laminate & 0.52 & 22 & 105 & $50 s^{-1}$ & n.a. & \\
\hline 53 & 8 & Glass/epoxy laminate & 0.52 & 22 & 105 & $40 s^{-1}$ & n.a. & \\
\hline 54 & 8 & Glass/epoxy laminate & 0.52 & 22 & 105 & $40 s^{-1}$ & n.a. & \\
\hline 55 & 72 & Carbon/polyamide6 laminate & 1.0 & 25 & 250 & $1 \mathrm{~mm} / \mathrm{min}$ & JISK7165 & Ma et al. 2016 [32] \\
\hline 56 & 58 & Carbon/epoxy laminate & 1.0 & 25 & 250 & $1 \mathrm{~mm} / \mathrm{min}$ & JISK7165 & \\
\hline 57 & 59 & Carbon/polyamide6 laminate & 1.0 & 15 & 250 & $1 \mathrm{~mm} / \mathrm{min}$ & D3039 & Ma et al. 2017 [33] \\
\hline 58 & 67 & Carbon/epoxy laminate & 1.0 & 15 & 250 & $1 \mathrm{~mm} / \mathrm{min}$ & D3039 & \\
\hline
\end{tabular}




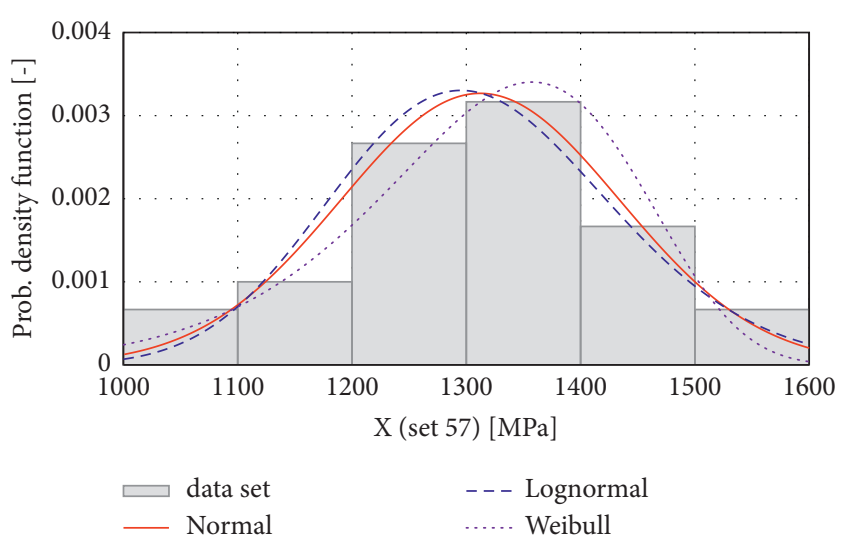

(a)

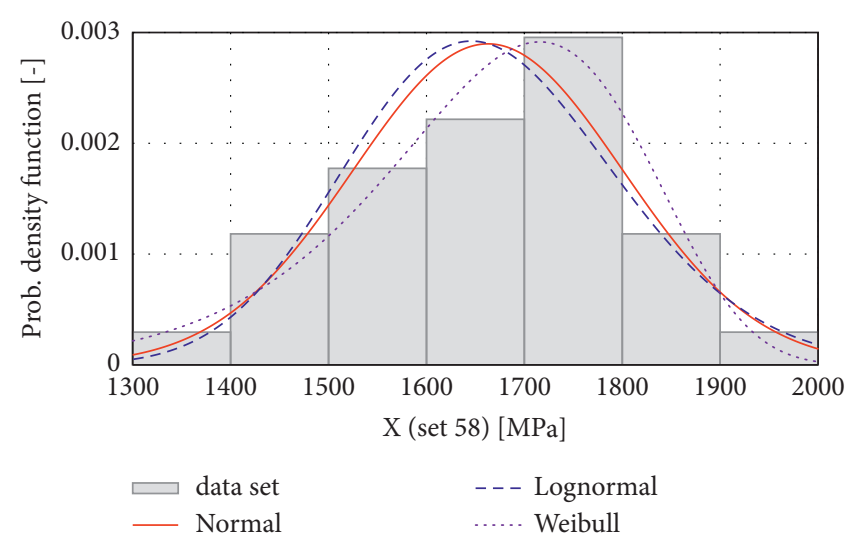

(b)

FIgURE 1: Histograms and fitted probability distributions for datasets. (a) Dataset 57 [33] and (b) dataset 58 [33].

estimated mean value from each dataset (sample) is smaller than $5 \%$ of the corresponding population mean with a $95 \%$ confidence level.

It should also be noted that different production techniques may result in different variations. For an overview of common production techniques, a reference is made, e.g., a JRC report [34]. It is an option to examine the datasets from different production techniques separately to distinguish variations from different production techniques. Similarly, variations due to differences in the fiber type, resin type, fiber orientation, and curing conditions should also be considered separately. Nevertheless, in this paper, the entire database is used to investigate the most appropriate stochastic model, and the analysis with respect to each dataset is conducted separately. In other words, the variation differences are inherently included in the analysis of each dataset, and such variation in any dataset is not necessarily connected to that in another dataset.

2.2. Maximum Likelihood Method. The parameters of each distribution function are estimated from test observations. The methods usually adopted for parameter estimation are as follows:

(i) The linear regression method

(ii) The moment method

(iii) The maximum likelihood method

Among these methods, the linear regression method is often used in cases where a linear relationship can be found. The moment method or its modified form is based on equating sample moments to the corresponding distribution moments. The maximum likelihood method is used to determine the parameters in such a way that the likelihood of the sample data is maximized. Although each of the methods can be used to determine the parameters of any of the mentioned distributions, the maximum likelihood method is chosen herein as it is generally used for the two-parameter Weibull distribution [5]. The maximum likelihood estimators (MLEs, i.e., $\widehat{\mu}$ and $\widehat{\sigma}$ for Normal and Lognormal; $\widehat{\alpha}$ and $\widehat{\beta}$ for Weibull) for each of the distributions can be obtained from equations (4)-(6). It is noted that the estimators for the
Weibull distribution cannot be obtained directly but can be obtained by root-finding techniques such as the Newton-Raphson method.

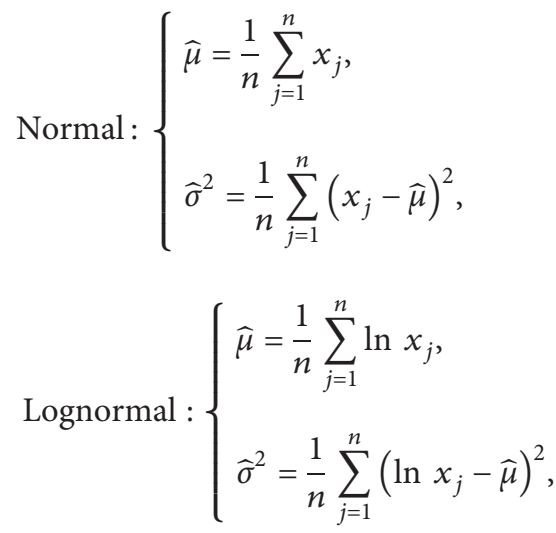

$$
\text { Weibull : }\left\{\begin{array}{l}
\widehat{\alpha}=\left(\frac{1}{n} \sum_{j=1}^{n} x_{j}^{\hat{\beta}}\right)^{(1 / \widehat{\beta})}, \\
\widehat{\beta}=\left(\frac{\sum_{j=1}^{n} x_{j}^{\beta} \ln x_{j}}{\sum_{j=1}^{n} x_{j}^{\hat{\beta}}}-\frac{1}{n} \sum_{j=1}^{n} \ln x_{j}\right)^{-1} .
\end{array}\right.
$$

2.3. Goodness of Fit. Various methods exist for determining the measure of goodness of fit for different probability distributions. For different experimental datasets, the probability distributions are generally similar in the central regions but differ vastly in the tail regions. Since the structural safety problem is very sensitive to the tail regions of the distributions involved, the indicator of goodness of fit is favored to reveal the (lower) tail regions for the selected datasets. In this study, the Anderson-Darling test method is adopted. This is because, in the Anderson-Darling test method, the weight function used in this test statistic has the effect of giving great importance to observations in the tail regions. In other words, this test statistic is sensitive to discrepancies in the tail regions [6]. 
The Anderson-Darling statistic is defined as

$A^{2}=\frac{1}{n} \sum_{i=1}^{n}\left[(1-2 i)\left\{\ln \left[F_{\theta}\left(x_{i}\right)\right]+\ln \left[1-F_{\theta}\left(x_{n+1-i}\right)\right]\right\}\right]-n$,

where $n$ is the sample size; $x_{i}$ is the $i$ th ascending-ordered sample point of the sample; and $F_{\theta}(x)$ is the cumulative distribution function with parameters in the vector $\theta$. For distributions with unknown parameters, the goodness-of-fit test is based on a cumulative distribution function with the estimated parameters, i.e., $F_{\widehat{\theta}}(x)$ in terms of the Benard median rank formula, which is given by

$$
F_{\widehat{\theta}}\left(x_{i}\right)=\frac{i-0.3}{n+0.4} \text {. }
$$

Furthermore, the Anderson-Darling statistic is modified as shown in equation (9) for the Normal and Lognormal distributions and as in equation (10) for the Weibull distribution. Then, the modified statistic is compared with the critical value at a given significance level.

$$
\begin{aligned}
\text { Normal/Lognormal }: A D & =\left(1+\frac{4}{n}-\frac{25}{n^{2}}\right) A^{2}, \\
\text { Weibull }: A D & =\left(1+\frac{0.2}{\sqrt{n}}\right) A^{2} .
\end{aligned}
$$

Another way is to follow Anderson-Darling statisticbased measures, such as the observed significance level (OSL) recommended in MLF-HDBK-17-1F [1]. Based on the Anderson-Darling statistic, the OSL is defined in equation (11) for the Normal and the Lognormal distributions and in equation (12) for the Weibull distribution.

$$
\begin{aligned}
\text { Normal/Lognormal : OSL } & =\frac{1}{1+\exp [-0.48+0.78 \ln A D+4.58 A D]}, \\
\text { Weibull : OSL } & =\frac{1}{1+\exp [-0.10+1.24 \ln A D+4.48 A D]} .
\end{aligned}
$$

The OSL is the probability of obtaining a value for the test statistic that is at least as extreme as the value calculated for the null hypothesis being true when the data are actually sampled from the distribution. The widely used significance level is 0.05; therefore, the null hypothesis is rejected if the OSL value obtained is less than 0.05 .

\subsection{Data Analysis and Discussion}

2.4.1. Overview of the Experimental Data. Figure 2 summarizes the geometric properties of all the collected experimental datasets. The majority of the specimens had a thickness between $1 \mathrm{~mm}$ and $5 \mathrm{~mm}$ (83.33\%, Figure 2(a)). Almost 86.67\% of the specimens had a width between $10 \mathrm{~mm}$ and $40 \mathrm{~mm}$ (Figure 2(b)). The length of the tested specimens was larger than $100 \mathrm{~mm}$ in most cases (85.36\%, Figure 2(c)). Figure 3 shows the frequencies for the average and the coefficient of variation (c.o.v.) with respect to tensile strength for all datasets. The average tensile strength for most specimens was less than $1500 \mathrm{MPa}(77.60 \%$, Figure 3(a)), and the majority of the dataset had a strength c.o.v. ranging from 0.025 to $0.10(82.76 \%$, Figure $3(\mathrm{~b})$ ). These observations illustrate that the presented experimental datasets cover a wide range of commonly used FRP composites for engineering applications. Regardless of the reinforced fiber type, each dataset shows relatively small variations. The coefficients of variation (c.o.v.) for all datasets range from 0.003 to 0.189 , and the average of c.o.v. is 0.063 . The relatively low c.o.v. values for the datasets indicate the efficiency of the referred experiments and prove that the adoption of these datasets is convincing for the use in the following fitting process in the present study.
2.4.2. Fitting Result Analysis. With the experimental database shown in Table 1, the OSL values for all datasets were evaluated and the results are shown in Table 2. Those OSL values that are lower than the selected significance level, i.e., 0.05 , for which the null hypothesis is rejected, are underlined. The average and c.o.v. values for the OSL values for each dataset group are shown in Figure 4. Regardless of the fiber type, the average OSL values for the Normal and Weibull distributions are comparable and slightly larger than that for the Lognormal distribution. For GFRP datasets, the average and c.o.v. for the OSL values for each distribution are also comparable. With respect to the CFRP datasets, the highest average (as well as c.o.v.) for the OSL values is referred to the Weibull distribution. The average and c.o.v. for the OSL values shown in Figure 4 indicate that the goodness of fit with respect to all three distributions is comparable.

The rejection cases for each distribution are shown in Table 3. It is shown that, out of 58 datasets, the Normal, the Lognormal, and the Weibull distributions are rejected by 5, 5 , and 7 datasets, respectively. When the reinforced fiber type is considered separately, it is found that the three distributions are respectively rejected by 1,1 , and 3 out of 31 GFRP datasets and are respectively rejected by 4,6 , and 4 out of 27 CFRP datasets.

Unlike the observations in reference [3] where the Weibull distribution was rejected in 3 out of 12 sets and neither the Normal nor Lognormal distributions can be rejected for any of the 12 sets, the observations herein show that for some sets (e.g., Sets 25, 44, and 49), the Weibull distribution cannot be rejected, whereas both the Normal and Lognormal distributions are rejected. As mentioned previously, many authors claim that, from the perspective of 


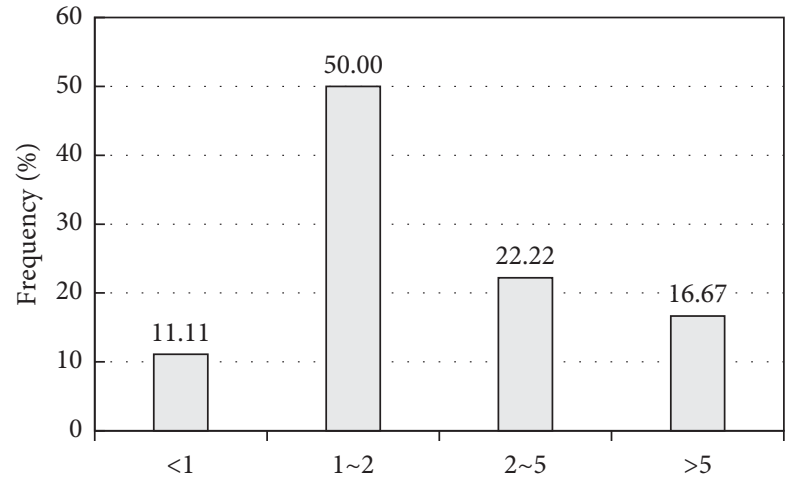

(a)

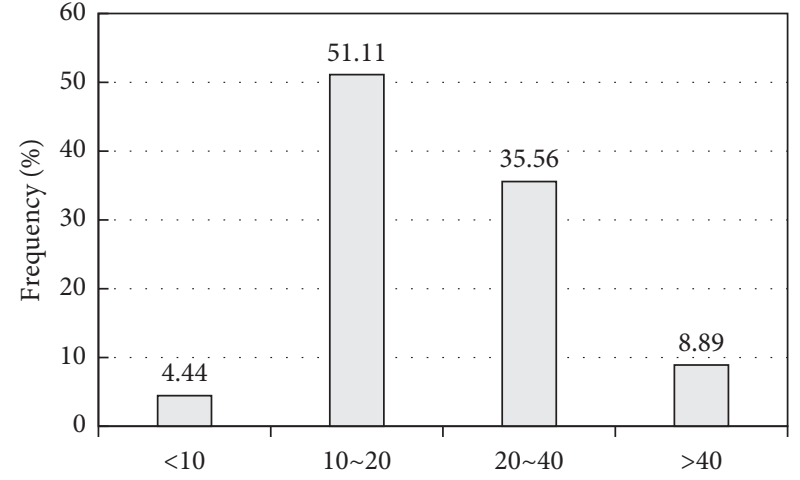

(b)

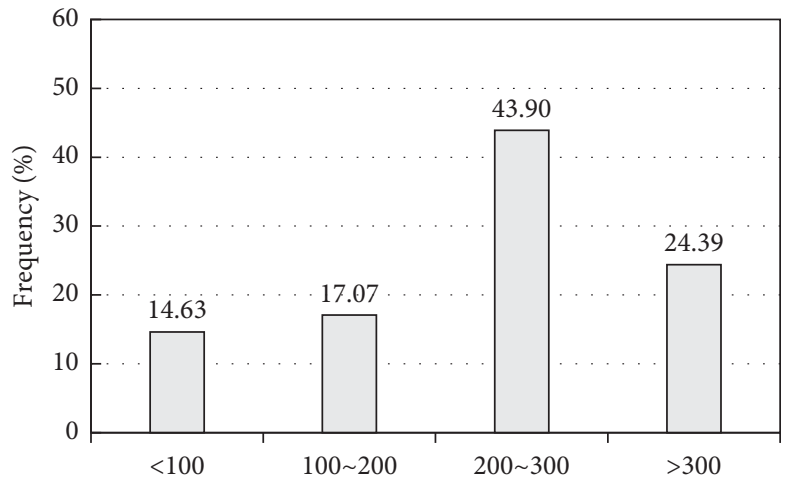

(c)

FIgURE 2: Distribution of the geometric properties of specimens. (a) Specimen thickness, (b) specimen width, and (c) specimen length.

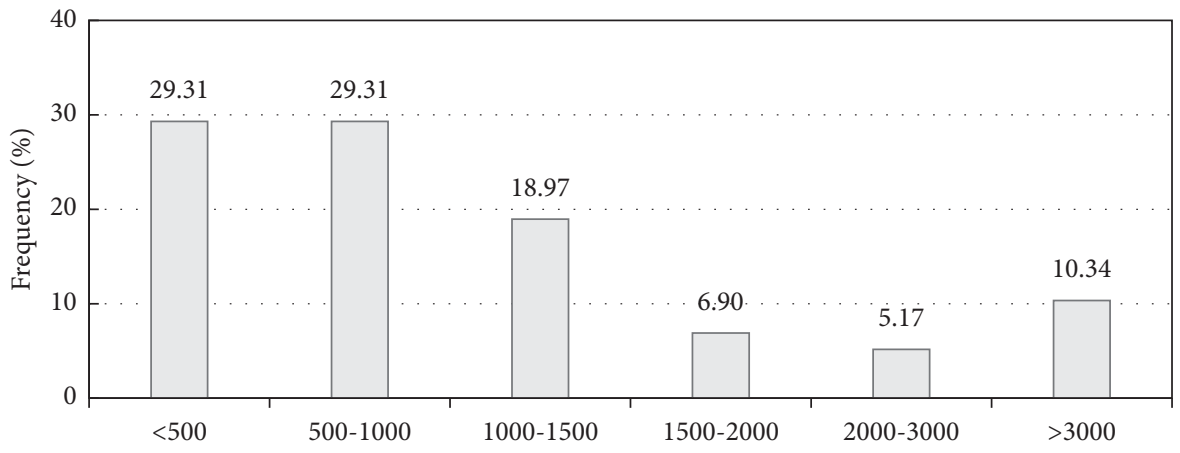

(a)

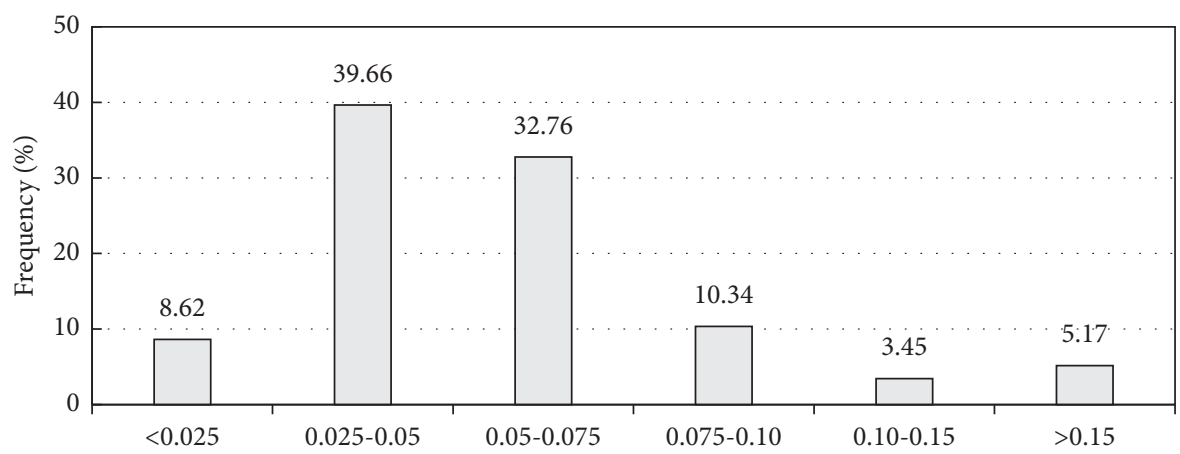

(b)

Figure 3: Distribution of the tensile strength. (a) Average of tensile strength and (b) c.o.v of tensile strength. 
TABLE 2: Statistics for the datasets and OSL for Normal, Lognormal, and Weibull distributions.

\begin{tabular}{|c|c|c|c|c|c|c|}
\hline \multirow{2}{*}{ Data set no. } & \multirow{2}{*}{ Sample size } & \multirow{2}{*}{ Fiber type } & \multirow{2}{*}{ c.o.v. } & \multicolumn{3}{|c|}{ OSL* } \\
\hline & & & & $\mathrm{N}$ & $\mathrm{LN}$ & $\mathrm{W}$ \\
\hline 1 & 7 & Glass & 0.048 & 0.466 & 0.487 & 0.243 \\
\hline 2 & 5 & Glass & 0.050 & 0.400 & 0.411 & 0.177 \\
\hline 3 & 6 & Glass & 0.058 & 0.503 & 0.474 & 0.596 \\
\hline 4 & 13 & Carbon & 0.045 & 0.254 & 0.319 & $0.049^{* *}$ \\
\hline 5 & 36 & Carbon & 0.040 & 0.195 & 0.252 & 0.017 \\
\hline 6 & 29 & Glass & 0.057 & 0.699 & 0.622 & 0.589 \\
\hline 7 & 25 & Carbon & 0.070 & 0.176 & 0.081 & 0.724 \\
\hline 8 & 20 & Carbon & 0.060 & 0.136 & 0.079 & 0.681 \\
\hline 9 & 36 & Carbon & 0.094 & 0.155 & $0.028^{* *}$ & 0.557 \\
\hline 10 & 49 & Glass & 0.100 & 0.338 & 0.152 & 0.333 \\
\hline 11 & 30 & Carbon & 0.055 & 0.596 & 0.527 & 0.522 \\
\hline 12 & 31 & Carbon & 0.111 & 0.583 & 0.570 & 0.144 \\
\hline 13 & 21 & Carbon & 0.104 & 0.469 & 0.317 & 0.793 \\
\hline 14 & 48 & Carbon & 0.157 & 0.654 & 0.495 & 0.221 \\
\hline 15 & 24 & Carbon & 0.090 & 0.353 & 0.200 & 0.801 \\
\hline 16 & 30 & Carbon & 0.094 & 0.500 & 0.571 & 0.153 \\
\hline 17 & 6 & Carbon & 0.052 & 0.694 & 0.665 & 0.773 \\
\hline 18 & 7 & Carbon & 0.030 & 0.413 & 0.427 & 0.286 \\
\hline 19 & 7 & Carbon & 0.041 & 0.552 & 0.569 & 0.458 \\
\hline 20 & 7 & Carbon & 0.026 & 0.356 & 0.328 & 0.695 \\
\hline 21 & 7 & Carbon & 0.061 & 0.584 & 0.568 & 0.618 \\
\hline 22 & 7 & Carbon & 0.050 & 0.448 & 0.410 & 0.667 \\
\hline 23 & 8 & Glass & 0.037 & 0.558 & 0.527 & 0.772 \\
\hline 24 & 14 & Glass & 0.045 & 0.524 & 0.501 & 0.540 \\
\hline 25 & 20 & Carbon & 0.068 & $0.025^{* *}$ & $0.009^{* *}$ & 0.278 \\
\hline 26 & 20 & Glass & 0.039 & 0.140 & 0.138 & 0.113 \\
\hline 27 & 19 & Carbon & 0.064 & 0.181 & 0.129 & 0.536 \\
\hline 28 & 6 & Glass & 0.037 & 0.177 & 0.167 & 0.203 \\
\hline 29 & 5 & Glass & 0.048 & 0.697 & 0.685 & 0.663 \\
\hline 30 & 5 & Glass & 0.026 & 0.619 & 0.632 & 0.288 \\
\hline 31 & 5 & Glass & 0.052 & 0.055 & 0.050 & $0.014^{* *}$ \\
\hline 32 & 5 & Glass & 0.051 & 0.783 & 0.790 & 0.638 \\
\hline 33 & 5 & Glass & 0.056 & 0.734 & 0.726 & 0.635 \\
\hline 34 & 30 & Glass & 0.074 & 0.113 & 0.195 & $0.009^{* *}$ \\
\hline 35 & 30 & Glass & 0.130 & 0.198 & 0.120 & 0.302 \\
\hline 36 & 24 & Glass & 0.102 & 0.142 & 0.147 & 0.136 \\
\hline 37 & 24 & Glass & 0.077 & 0.142 & 0.260 & $0.008^{* *}$ \\
\hline 38 & 30 & Glass & 0.069 & 0.757 & 0.684 & 0.699 \\
\hline 39 & 5 & Glass & 0.003 & 0.400 & 0.399 & 0.329 \\
\hline 40 & 5 & Glass & 0.008 & 0.795 & 0.796 & 0.610 \\
\hline 41 & 5 & Glass & 0.010 & 0.511 & 0.513 & 0.317 \\
\hline 42 & 5 & Glass & 0.026 & 0.717 & 0.716 & 0.594 \\
\hline 43 & 5 & Glass & 0.008 & 0.550 & 0.551 & 0.347 \\
\hline 44 & 30 & Carbon & 0.043 & $0.049^{* *}$ & $0.040^{* *}$ & 0.115 \\
\hline 45 & 20 & Carbon & 0.047 & 0.122 & 0.188 & $0.006^{* *}$ \\
\hline 46 & 20 & Carbon & 0.047 & $0.021^{* *}$ & $0.020^{* *}$ & $0.021^{* *}$ \\
\hline 47 & 7 & Glass & 0.025 & 0.525 & 0.544 & 0.307 \\
\hline 48 & 60 & Carbon & 0.058 & 0.615 & 0.562 & 0.272 \\
\hline 49 & 9 & Glass & 0.072 & $0.027^{* *}$ & $0.018^{* *}$ & 0.123 \\
\hline 50 & 8 & Glass & 0.065 & 0.440 & 0.370 & 0.748 \\
\hline 51 & 10 & Glass & 0.074 & 0.510 & 0.487 & 0.628 \\
\hline 52 & 9 & Glass & 0.057 & 0.551 & 0.603 & 0.389 \\
\hline 53 & 8 & Glass & 0.032 & 0.433 & 0.433 & 0.470 \\
\hline 54 & 8 & Glass & 0.048 & 0.169 & 0.182 & 0.098 \\
\hline 55 & 72 & Carbon & 0.180 & $0.001^{* *}$ & $0.003^{* *}$ & $0.001^{* *}$ \\
\hline 56 & 58 & Carbon & 0.189 & 0.088 & $0.048^{* *}$ & 0.113 \\
\hline 57 & 59 & Carbon & 0.093 & 0.360 & 0.185 & 0.522 \\
\hline \multirow[t]{3}{*}{58} & 67 & Carbon & 0.083 & 0.476 & 0.326 & 0.302 \\
\hline & Average & & 0.063 & 0.392 & 0.367 & 0.384 \\
\hline & c.o.v. & & 0.038 & 0.233 & 0.234 & 0.255 \\
\hline
\end{tabular}

*Some of the experimental data displayed were digitized using graphs obtained from the respective references; thus, a small systematic error could be present. ${ }^{* *}$ Values of OSL $<0.05$, for which the null hypothesis is rejected, are underlined. 


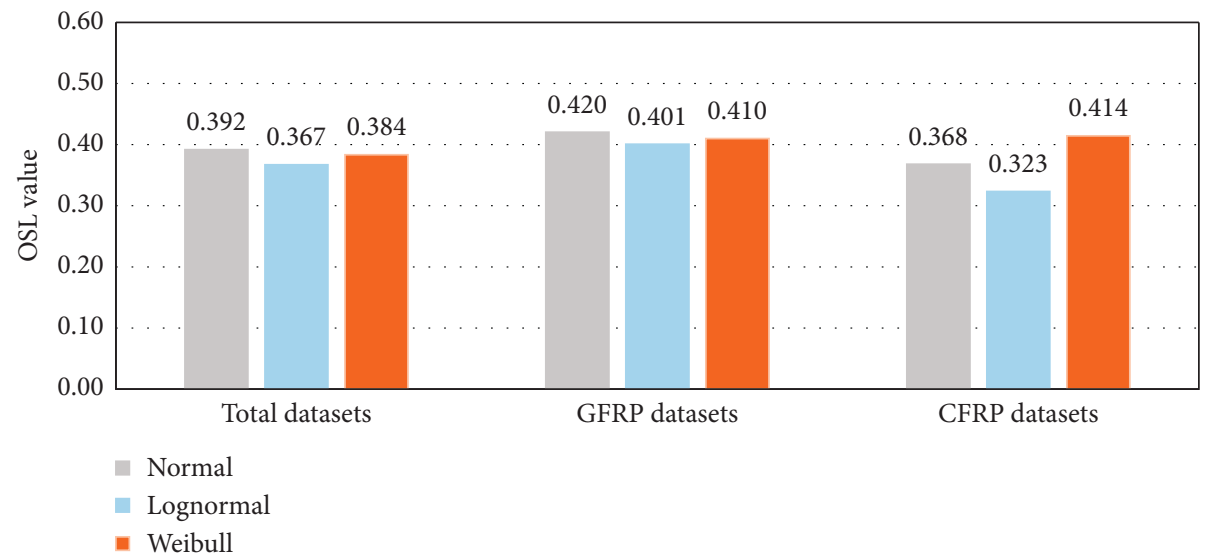

(a)

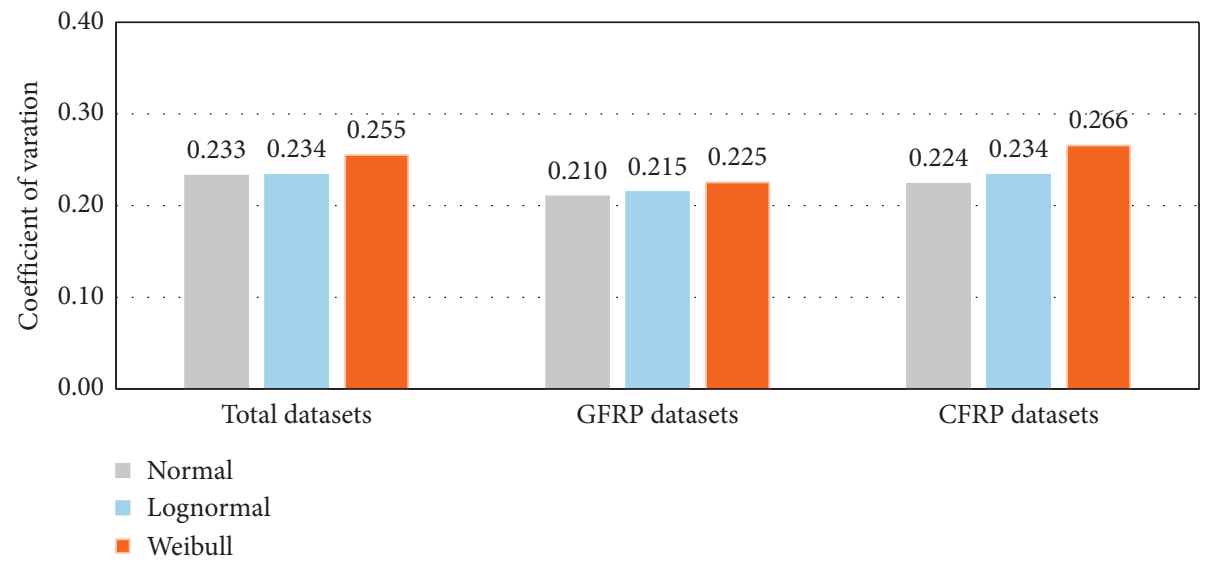

(b)

FIgure 4: The statistics for the OSL values. (a) Averaged OSL values and (b) c.o.v. of the OSL values.

TABLE 3: Rejection of fitting results (values in brackets are the rejection ratios).

\begin{tabular}{lccc}
\hline Dataset & Normal & Lognormal & Weibull \\
\hline Total (58 datasets) & $5(8.62 \%)$ & $5(12.07 \%)$ & $7(12.07 \%)$ \\
GFRP (31 datasets) & $1(3.23 \%)$ & $1(3.23 \%)$ & $3(9.68 \%)$ \\
CFRP (27 datasets) & $4(14.81 \%)$ & $6(22.22 \%)$ & $4(14.81 \%)$ \\
\hline
\end{tabular}

experimental justification, the Weibull distribution is the best option to model the tensile strength of FRP composites. However, the observations from Table 3 do not agree with this opinion. Actually, for the GFRP dataset group, the rejection ratio for the Weibull distribution (9.68\%) is higher than that for the Normal (3.23\%) or the Lognormal (3.23\%) distribution. Table 3 shows that the rejection ratios for all the three distributions are relatively low. It can be concluded that all three distributions can be used to model the tensile strength of FRP composites when the experimental justification result is taken as the unique basis. To find out the most recommended option among these three distributions, more evidence should be provided. In the following section, further analysis is performed from the perspective of the design-orientated probabilistic model.

\section{Probabilistic Model of the Tensile Strength of FRP Composites for Structural Design}

3.1. Characteristic Value. As described in Fib Bulletin 14 [35], which is adapted from Eurocode 0 [36], unless otherwise specified, the characteristic value of the used FRP composites, $f_{f k}$, corresponds to the $5 \%$ fractile of the tensile strength. By using the probability density function in equations (1)-(3), the $p$-percentile value, i.e., the value such that $P\left[X<x_{p}\right]=p$, is given by

Normal: $x_{p}=\mu+\sigma z_{p}$,

Lognormal: $x_{p}=\exp \left[\left(\frac{\mu^{2}}{\sqrt{\sigma^{2}+\mu^{2}}}\right)+z_{p} \sqrt{\log \left(\frac{\sigma^{2}}{\mu^{2}+1}\right)}\right]$,

Weibull: $x_{p}=\alpha[-\ln (1-p)]^{1 / \beta}$,

where $z_{p}$ is the inverse of the standard normal cumulative distribution function at the corresponding probability $p$. Therefore, the estimated characteristic value for the tensile 
strength of FRP composites based on MLEs (i.e., the parameter estimators in equations (4)-(6)) is defined by

Normal : $\widehat{f}_{f k}=\widehat{x}_{0.05}=\widehat{\mu}-1.645 \widehat{\sigma}$,

Lognormal: $\widehat{f}_{f k}=\widehat{x}_{0.05}$

$$
=\exp \left[\left(\frac{\mu^{2}}{\sqrt{\hat{\sigma}^{2}+\widehat{\mu}^{2}}}\right)-1.645 \sqrt{\log \left(\frac{\widehat{\sigma}^{2}}{\hat{\mu}^{2}+1}\right)}\right]
$$

Weibull: $\widehat{f}_{f k}=\widehat{x}_{0.05}=\widehat{\alpha}[-\ln (1-0.05)]^{(1 / \widehat{\beta})}=\widehat{\alpha}[0.0513]^{(1 / \widehat{\beta})}$.

Many researchers (e.g., Zureick et al. [3]) have pointed out that the Weibull distribution usually provides higher safety margins with respect to design values when compared to the Normal or Lognormal distributions. The estimated characteristic values (i.e., $5^{\text {th }}$ percentile lower bound) divided by the sample mean for all 58 datasets using the three distributions are shown in Table 4 . The ratio for this estimated fractile derived from the Normal and Lognormal distributions to that from the Weibull distribution (i.e., $\left(\widehat{x}_{0.05}(N) / \widehat{x}_{0.05}(W)\right)$ and $\left.\left(\widehat{x}_{0.05}(L N) / \widehat{x}_{0.05}(W)\right)\right)$ is plotted in Figure 5. Clearly, almost all the datasets (except for two datasets) show that the estimated characteristic tensile strength obtained from the Normal and the Lognormal distributions is larger than that obtained from the Weibull distribution. Considering Set 14 for instance, the OSL values for three distributions (i.e., $0.654(\mathrm{~N}), 0.495(\mathrm{LN})$, and 0.221 (W)) are all larger than the significance level 0.05. Therefore, the hypothesis cannot be rejected for any of these distributions. It is found that the $5^{\text {th }}$ percentile lower bounds over the sample mean corresponding to the Normal and the Lognormal distributions are 0.744 and 0.760 , indicating an $8.4 \%$ and $10.8 \%$ higher than that derived from the Weibull distribution $\left(\hat{x}_{0.05}(\mathrm{~W}) / \bar{x}=0.686\right)$, respectively. This observation indicates that, for the same dataset, the adoption of the Weibull distribution for engineering design provides more conservativeness than the adoption of the Normal or the Lognormal distribution.

3.2. Statistical Uncertainty. As known, the quality of the MLE estimators is affected by the sample size. The statistical uncertainty of these parameters provides the basis for confidence levels that show the accuracy of the parameter estimates. The estimate of $x_{\mathrm{p}}$, i.e., $\widehat{x}_{p}$, has its own distribution depending on the distributions of the parameter estimates (e.g., $\widehat{\alpha}$ and $\widehat{\beta}$ for the Weibull distribution). This distribution is used to obtain the $p$-percentile with a given confidence $\gamma$, i.e., $\widehat{x}_{p, \gamma}$, which means there is a $\gamma \times 100 \%$ confidence that $(1-p) \times 100 \%$ of the population will be above this value. $\hat{x}_{p, \gamma}$ is often referred to as the $\gamma \times 100 \%$ lower confidence bound on the $p$-percentile of a specified population of measurements. Unfortunately, the distributions for the
TABle 4: The $5^{\text {th }}$ percentile characteristic values.

\begin{tabular}{|c|c|c|c|c|c|}
\hline \multirow{2}{*}{ Set no. } & \multirow{2}{*}{ Sample size } & \multirow{2}{*}{ Fiber type } & \multicolumn{3}{|c|}{$\widehat{x}_{0.05} / \bar{x}$} \\
\hline & & & $\mathrm{N}$ & $\mathrm{LN}$ & $\mathrm{W}$ \\
\hline 1 & 7 & Glass & 0.926 & 0.928 & 0.893 \\
\hline 2 & 5 & Glass & 0.926 & 0.928 & 0.908 \\
\hline 3 & 6 & Glass & 0.913 & 0.914 & 0.906 \\
\hline 4 & 13 & Carbon & 0.929 & 0.931 & 0.888 \\
\hline 5 & 36 & Carbon & 0.935 & 0.937 & 0.908 \\
\hline 6 & 29 & Glass & 0.907 & 0.909 & 0.884 \\
\hline 7 & 25 & Carbon & 0.886 & 0.887 & 0.873 \\
\hline 8 & 20 & Carbon & 0.904 & 0.905 & 0.896 \\
\hline 9 & 36 & Carbon & 0.848 & 0.848 & 0.831 \\
\hline 10 & 49 & Glass & 0.837 & 0.841 & 0.815 \\
\hline 11 & 30 & Carbon & 0.912 & 0.913 & 0.890 \\
\hline 12 & 31 & Carbon & 0.821 & 0.828 & 0.772 \\
\hline 13 & 21 & Carbon & 0.834 & 0.839 & 0.807 \\
\hline 14 & 48 & Carbon & 0.744 & 0.760 & 0.686 \\
\hline 15 & 24 & Carbon & 0.855 & 0.859 & 0.838 \\
\hline 16 & 30 & Carbon & 0.848 & 0.855 & 0.810 \\
\hline 17 & 6 & Carbon & 0.922 & 0.923 & 0.907 \\
\hline 18 & 7 & Carbon & 0.955 & 0.956 & 0.937 \\
\hline 19 & 7 & Carbon & 0.938 & 0.939 & 0.914 \\
\hline 20 & 7 & Carbon & 0.960 & 0.960 & 0.957 \\
\hline 21 & 7 & Carbon & 0.907 & 0.909 & 0.882 \\
\hline 22 & 7 & Carbon & 0.924 & 0.925 & 0.920 \\
\hline 23 & 8 & Glass & 0.944 & 0.944 & 0.933 \\
\hline 24 & 14 & Glass & 0.928 & 0.929 & 0.913 \\
\hline 25 & 20 & Carbon & 0.891 & 0.890 & 0.878 \\
\hline 26 & 20 & Glass & 0.937 & 0.938 & 0.926 \\
\hline 27 & 19 & Carbon & 0.897 & 0.899 & 0.879 \\
\hline 28 & 6 & Glass & 0.945 & 0.945 & 0.942 \\
\hline 29 & 5 & Glass & 0.930 & 0.931 & 0.922 \\
\hline 30 & 5 & Glass & 0.961 & 0.962 & 0.942 \\
\hline 31 & 5 & Glass & 0.923 & 0.923 & 0.944 \\
\hline 32 & 5 & Glass & 0.925 & 0.927 & 0.900 \\
\hline 33 & 5 & Glass & 0.918 & 0.920 & 0.896 \\
\hline 38 & 30 & Glass & 0.888 & 0.891 & 0.863 \\
\hline 39 & 5 & Glass & 0.996 & 0.996 & 0.995 \\
\hline 40 & 5 & Glass & 0.988 & 0.988 & 0.982 \\
\hline 41 & 5 & Glass & 0.985 & 0.985 & 0.978 \\
\hline 42 & 5 & Glass & 0.962 & 0.962 & 0.950 \\
\hline 43 & 5 & Glass & 0.988 & 0.989 & 0.985 \\
\hline 44 & 30 & Carbon & 0.930 & 0.931 & 0.921 \\
\hline 45 & 20 & Carbon & 0.924 & 0.927 & 0.881 \\
\hline 46 & 20 & Carbon & 0.925 & 0.926 & 0.916 \\
\hline 47 & 7 & Glass & 0.962 & 0.962 & 0.943 \\
\hline 48 & 60 & Carbon & 0.905 & 0.907 & 0.880 \\
\hline 49 & 9 & Glass & 0.889 & 0.887 & 0.906 \\
\hline 50 & 8 & Glass & 0.900 & 0.901 & 0.897 \\
\hline 51 & 10 & Glass & 0.885 & 0.888 & 0.865 \\
\hline 52 & 9 & Glass & 0.912 & 0.915 & 0.877 \\
\hline 53 & 8 & Glass & 0.951 & 0.952 & 0.941 \\
\hline 54 & 8 & Glass & 0.926 & 0.928 & 0.910 \\
\hline 55 & 72 & Carbon & 0.706 & 0.742 & 0.635 \\
\hline 56 & 58 & Carbon & 0.691 & 0.716 & 0.657 \\
\hline 57 & 59 & Carbon & 0.848 & 0.853 & 0.823 \\
\hline 58 & 67 & Carbon & 0.865 & 0.869 & 0.834 \\
\hline & Average & & 0.905 & 0.908 & 0.886 \\
\hline & c.o.v. & & 0.062 & 0.057 & 0.073 \\
\hline
\end{tabular}




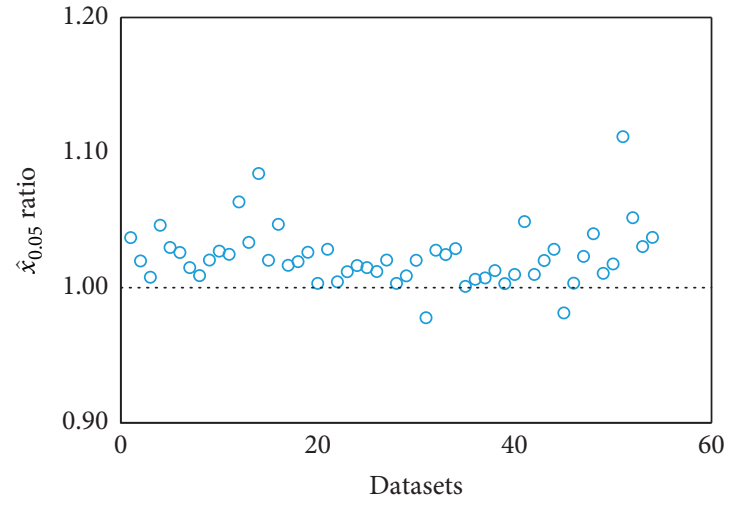

(a)

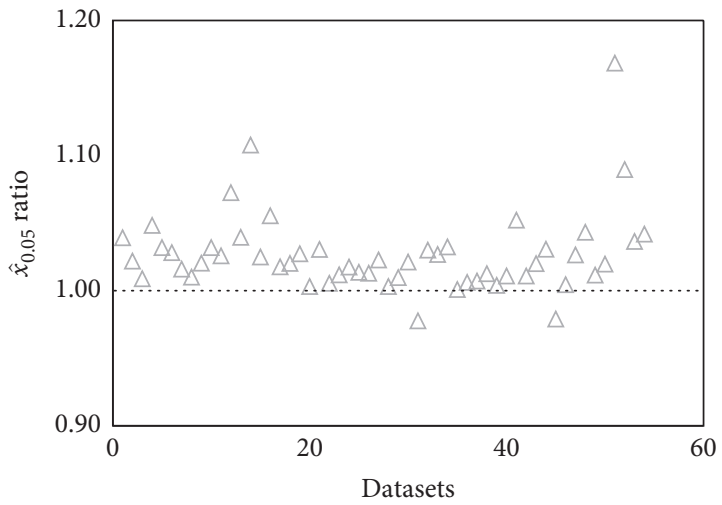

(b)

FIgURE 5: The ratio of the $5^{\text {th }}$ percentile lower bound for (a) the Normal distribution and (b) the Lognormal distribution to the Weibull distribution.

parameter estimators are not always available in a closed form. In case the Weibull distribution is involved, for example, modern computational techniques such as Monte Carlo simulation are usually adopted to quantify the statistical uncertainty of the parameter estimates.

In the work in reference [3], a so-called data confidence factor (i.e., the ratio of $\hat{x}_{p, \gamma}$ to $\hat{x}_{p}$ ) was investigated by adopting the method proposed by Bain and Engelhardt [37] and compared with that used in wood design. It should be noted that the adoption of this method requires an extensive tabulated database (e.g., Table 4 in reference [37]), which is obtained by the Monte Carlo simulation for different cases. Then, for the purpose of further usage, another extensive tabulated database for the data confidence factor needs to be generated for different confidence levels, $p$ values, $\gamma$ values, and sample sizes (an example can be found in reference [3]). In case no such table is available, it is not convenient to use this method, and approximate methods such as the one proposed by Bain and Engelhardt [38] can be adopted. In this method, the $\gamma \times 100 \%$ lower confidence bound for $x_{p}$ based on MLEs is given by

$$
\begin{aligned}
& \text { Normal: } \widehat{x}_{p, \gamma}=\widehat{\mu}-t_{\gamma}\left(n-1,-\sqrt{n} z_{p}\right) \cdot \frac{\widehat{\sigma}}{\sqrt{n}} \\
& \text { Lognormal: } \widehat{x}_{p, \gamma}=\exp \left[\log \left(\frac{\widehat{\mu}^{2}}{\sqrt{\widehat{\sigma}^{2}+\widehat{\mu}^{2}}}\right)-t_{\gamma}\left(n-1,-\sqrt{n} z_{p}\right) \cdots \sqrt{\frac{\log \left(\hat{\sigma}^{2} / \widehat{\mu}^{2}+1\right)}{n}}\right], \\
& \text { Weibull: } \widehat{x}_{p, \gamma}=\exp \left(\ln \hat{\alpha}-\frac{t_{\gamma}}{\hat{\beta} \sqrt{n-1}}\right),
\end{aligned}
$$

where $n$ is the sample size; the MLE estimators $\widehat{\mu}, \widehat{\sigma}, \widehat{\alpha}$, and $\widehat{\beta}$ can be obtained according to equations (4)-(6); $z_{p}$ is the inverse of the standard normal cumulative distribution function at the corresponding probability $p$; and $t \gamma$ is the inverse of the noncentral $t$ cumulative density function with $(n-1)$ degrees of freedom and noncentrality parameter $-\sqrt{n} \ln (-\ln (1-p))$ corresponding to a probability $\gamma$.

This method used herein is first compared with the method used in reference [3]. In this study, the $90^{\text {th }}$ percent confidence for the $5^{\text {th }}$ percentile of the sample of 24 tensile specimens VG $13-18$ is calculated with $\widehat{\alpha}=480.91 \mathrm{MPa}$ and $\widehat{\beta}=75.57 \mathrm{MPa}$. The value of $\widehat{x}_{0.05,0.90}$ is calculated to be $341.36 \mathrm{MPa}$, which is $2 \%$ higher than the calculated value of $334.40 \mathrm{MPa}$ in reference [3]. This indicates that this simple approximate method is sufficiently accurate for practical purposes.
3.3. Probabilistic Model for Structural Design Based on Regression Analysis. Since the coverage method with a significance level of $75 \%$ is approximately identical to Bayesian estimations with vague priors (as described in Eurocode 0 [36]), the 75\% confidence level is adopted in this study. For other significance levels, procedures similar to those described in the following sections can also be applied where necessary.

With respect to the characteristic value of the tensile strength for the adopted datasets, the values for $\hat{x}_{0.05,0.75}$ divided by the sample mean are given in Table 5 . The estimated lower bounds with $75 \%$ confidence obtained from the Normal and Lognormal distributions are compared with those obtained from the Weibull distribution (i.e., by analyzing the ratios $\left(\widehat{x}_{0.05,0.75}(N) / \widehat{x}_{0.05,0.75}(W)\right)$ and 
TABle 5: The $5^{\text {th }}$ percentile characteristic value with a $75 \%$ confidence level.

\begin{tabular}{|c|c|c|c|c|c|c|c|c|}
\hline \multirow{2}{*}{ Set no. } & \multirow{2}{*}{ Sample size } & \multirow{2}{*}{ Fiber type } & \multicolumn{3}{|c|}{$\left(\widehat{x}_{0.05,0.75} / \bar{x}\right)$} & \multicolumn{3}{|c|}{$\widehat{x}_{0.05,0.75} / \widehat{x}_{0.05}$} \\
\hline & & & $\mathrm{N}$ & $\mathrm{LN}$ & W & $\mathrm{N}$ & $\mathrm{LN}$ & $\mathrm{W}$ \\
\hline 1 & 7 & Glass & 0.899 & 0.904 & 0.854 & 0.971 & 0.973 & 0.956 \\
\hline 2 & 5 & Glass & 0.890 & 0.895 & 0.860 & 0.960 & 0.964 & 0.947 \\
\hline 3 & 6 & Glass & 0.876 & 0.880 & 0.865 & 0.960 & 0.963 & 0.954 \\
\hline 4 & 13 & Carbon & 0.912 & 0.916 & 0.863 & 0.982 & 0.984 & 0.972 \\
\hline 5 & 36 & Carbon & 0.928 & 0.930 & 0.897 & 0.992 & 0.992 & 0.988 \\
\hline 6 & 29 & Glass & 0.894 & 0.897 & 0.868 & 0.986 & 0.987 & 0.982 \\
\hline 7 & 25 & Carbon & 0.869 & 0.872 & 0.854 & 0.981 & 0.982 & 0.978 \\
\hline 8 & 20 & Carbon & 0.887 & 0.889 & 0.878 & 0.981 & 0.983 & 0.980 \\
\hline 9 & 36 & Carbon & 0.829 & 0.831 & 0.811 & 0.978 & 0.981 & 0.977 \\
\hline 10 & 49 & Glass & 0.821 & 0.827 & 0.797 & 0.980 & 0.983 & 0.978 \\
\hline 11 & 30 & Carbon & 0.900 & 0.902 & 0.876 & 0.987 & 0.988 & 0.983 \\
\hline 12 & 31 & Carbon & 0.797 & 0.808 & 0.746 & 0.971 & 0.976 & 0.965 \\
\hline 13 & 21 & Carbon & 0.806 & 0.815 & 0.777 & 0.966 & 0.972 & 0.962 \\
\hline 14 & 48 & Carbon & 0.717 & 0.740 & 0.659 & 0.964 & 0.973 & 0.961 \\
\hline 15 & 24 & Carbon & 0.833 & 0.839 & 0.813 & 0.974 & 0.977 & 0.971 \\
\hline 16 & 30 & Carbon & 0.827 & 0.837 & 0.786 & 0.976 & 0.979 & 0.971 \\
\hline 17 & 6 & Carbon & 0.889 & 0.893 & 0.866 & 0.964 & 0.967 & 0.955 \\
\hline 18 & 7 & Carbon & 0.938 & 0.940 & 0.912 & 0.983 & 0.984 & 0.974 \\
\hline 19 & 7 & Carbon & 0.915 & 0.918 & 0.881 & 0.975 & 0.977 & 0.964 \\
\hline 20 & 7 & Carbon & 0.945 & 0.946 & 0.940 & 0.985 & 0.985 & 0.982 \\
\hline 21 & 7 & Carbon & 0.872 & 0.878 & 0.838 & 0.962 & 0.966 & 0.950 \\
\hline 22 & 7 & Carbon & 0.896 & 0.899 & 0.889 & 0.970 & 0.972 & 0.966 \\
\hline 23 & 8 & Glass & 0.925 & 0.927 & 0.910 & 0.980 & 0.981 & 0.975 \\
\hline 24 & 14 & Glass & 0.912 & 0.914 & 0.893 & 0.983 & 0.984 & 0.979 \\
\hline 25 & 20 & Carbon & 0.871 & 0.873 & 0.857 & 0.979 & 0.980 & 0.976 \\
\hline 26 & 20 & Glass & 0.926 & 0.928 & 0.913 & 0.988 & 0.989 & 0.986 \\
\hline 27 & 19 & Carbon & 0.879 & 0.882 & 0.857 & 0.979 & 0.981 & 0.975 \\
\hline 28 & 6 & Glass & 0.922 & 0.924 & 0.915 & 0.975 & 0.977 & 0.971 \\
\hline 29 & 5 & Glass & 0.895 & 0.898 & 0.880 & 0.962 & 0.965 & 0.955 \\
\hline 30 & 5 & Glass & 0.942 & 0.944 & 0.911 & 0.980 & 0.981 & 0.967 \\
\hline 31 & 5 & Glass & 0.885 & 0.887 & 0.912 & 0.959 & 0.961 & 0.966 \\
\hline 32 & 5 & Glass & 0.888 & 0.894 & 0.849 & 0.960 & 0.964 & 0.943 \\
\hline 33 & 5 & Glass & 0.877 & 0.882 & 0.842 & 0.955 & 0.960 & 0.940 \\
\hline 38 & 30 & Glass & 0.873 & 0.878 & 0.845 & 0.983 & 0.985 & 0.979 \\
\hline 39 & 5 & Glass & 0.994 & 0.994 & 0.992 & 0.998 & 0.998 & 0.997 \\
\hline 40 & 5 & Glass & 0.981 & 0.982 & 0.973 & 0.994 & 0.994 & 0.990 \\
\hline 41 & 5 & Glass & 0.977 & 0.977 & 0.966 & 0.992 & 0.992 & 0.988 \\
\hline 42 & 5 & Glass & 0.943 & 0.944 & 0.923 & 0.980 & 0.981 & 0.972 \\
\hline 43 & 5 & Glass & 0.983 & 0.983 & 0.976 & 0.994 & 0.994 & 0.991 \\
\hline 44 & 30 & Carbon & 0.921 & 0.922 & 0.910 & 0.990 & 0.990 & 0.988 \\
\hline 45 & 20 & Carbon & 0.911 & 0.915 & 0.861 & 0.986 & 0.987 & 0.977 \\
\hline 46 & 20 & Carbon & 0.912 & 0.914 & 0.901 & 0.986 & 0.987 & 0.984 \\
\hline 47 & 7 & Glass & 0.947 & 0.949 & 0.921 & 0.985 & 0.986 & 0.977 \\
\hline 48 & 60 & Carbon & 0.896 & 0.899 & 0.869 & 0.990 & 0.991 & 0.988 \\
\hline 49 & 9 & Glass & 0.856 & 0.856 & 0.876 & 0.962 & 0.965 & 0.967 \\
\hline 50 & 8 & Glass & 0.867 & 0.870 & 0.862 & 0.963 & 0.967 & 0.961 \\
\hline 51 & 10 & Glass & 0.853 & 0.860 & 0.828 & 0.964 & 0.968 & 0.957 \\
\hline 52 & 9 & Glass & 0.885 & 0.891 & 0.841 & 0.971 & 0.974 & 0.958 \\
\hline 53 & 8 & Glass & 0.935 & 0.937 & 0.920 & 0.983 & 0.984 & 0.978 \\
\hline 54 & 8 & Glass & 0.902 & 0.905 & 0.879 & 0.974 & 0.976 & 0.966 \\
\hline 55 & 72 & Carbon & 0.682 & 0.725 & 0.612 & 0.966 & 0.977 & 0.963 \\
\hline 56 & 58 & Carbon & 0.663 & 0.695 & 0.631 & 0.959 & 0.971 & 0.961 \\
\hline 57 & 59 & Carbon & 0.834 & 0.841 & 0.808 & 0.984 & 0.986 & 0.982 \\
\hline \multirow{3}{*}{58} & 67 & Carbon & 0.853 & 0.859 & 0.821 & 0.987 & 0.988 & 0.984 \\
\hline & Average & & 0.884 & 0.889 & 0.861 & 0.977 & 0.979 & 0.971 \\
\hline & c.o.v. & & 0.065 & 0.059 & 0.074 & 0.011 & 0.010 & 0.013 \\
\hline
\end{tabular}




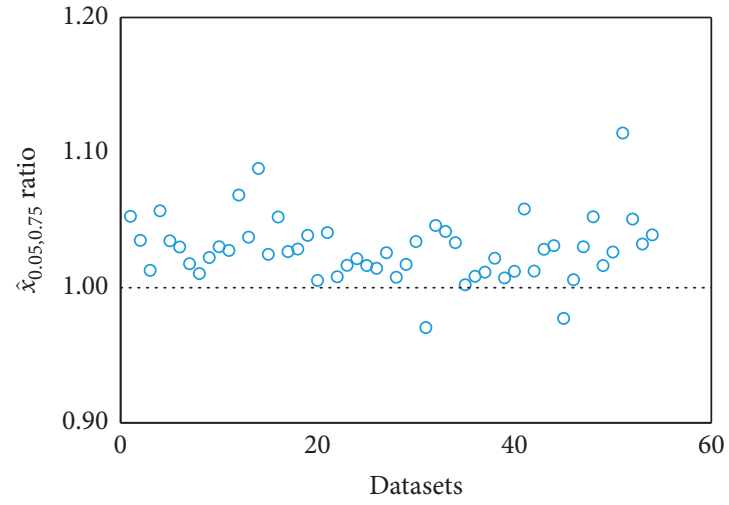

(a)

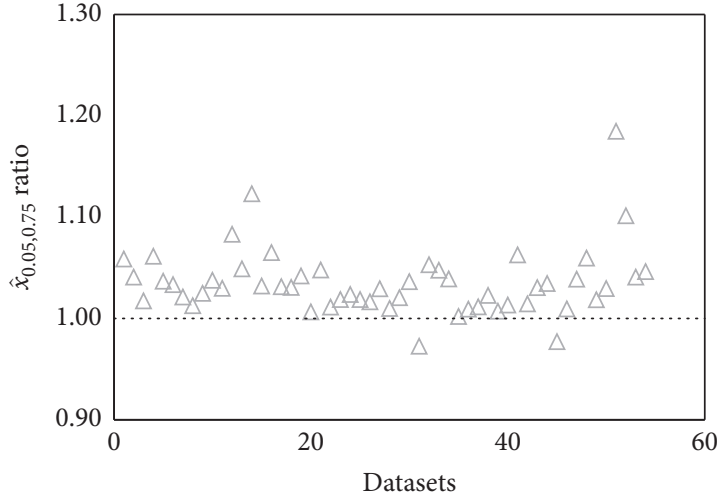

(b)

Figure 6: The ratio of the $5^{\text {th }}$ percentile lower bound at a $75 \%$ confidence level for (a) the Normal distribution and (b) the Lognormal distribution to the Weibull distribution.

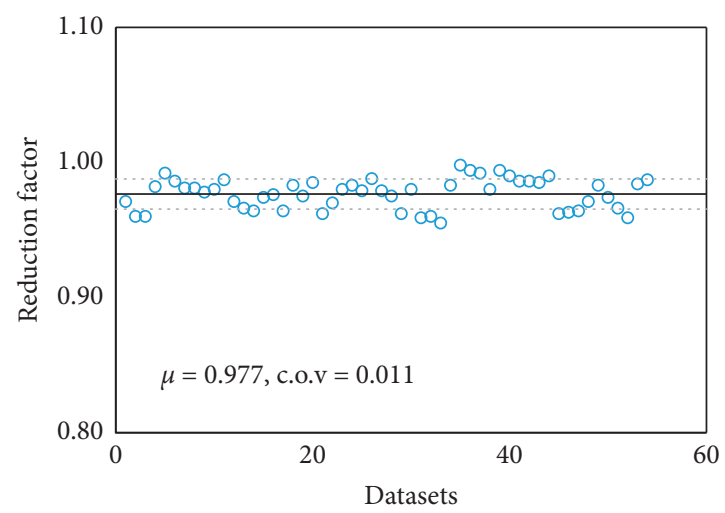

(a)

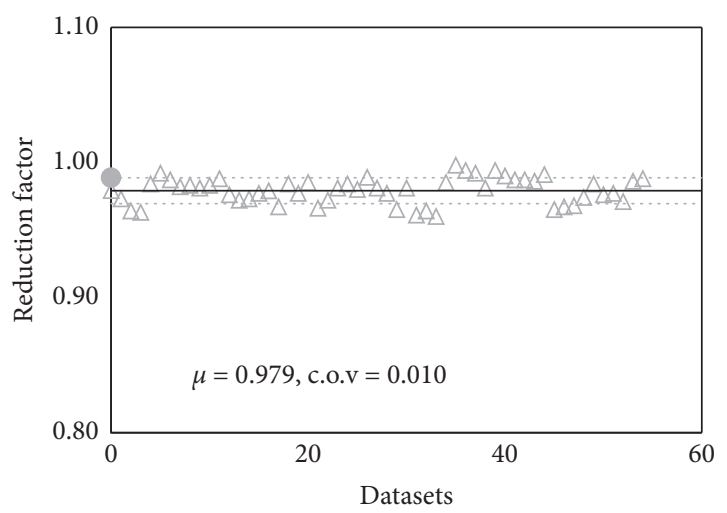

(b)

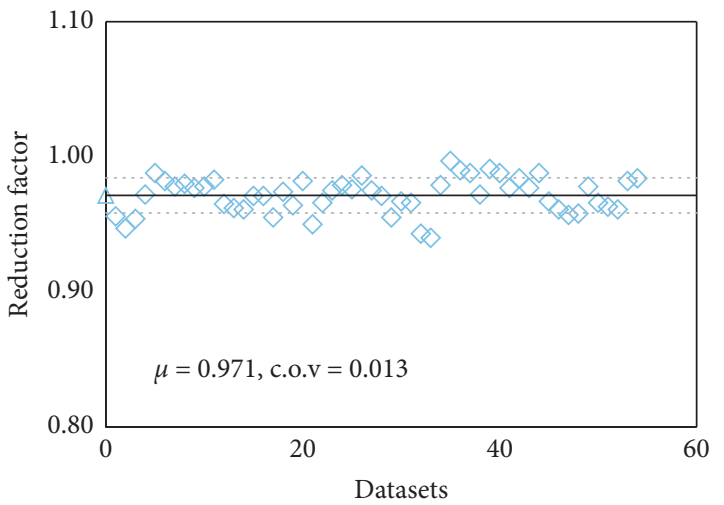

(c)

Figure 7: The reduction factor for (a) the Normal, (b) the Lognormal, and (c) the Weibull distributions.

$\left(\widehat{x}_{0.05,0.75}(L N) / \widehat{x}_{0.05,0.75}(W)\right)$, as plotted in Figure 6. Figure 6 shows that the Weibull distribution provides a greater safety margin with respect to structural design than the Normal and the Lognormal distributions, which is consistent to the findings in Figure 5. This means that, whether or not the statistical uncertainty is considered, the selection of the Weibull distribution to model the tensile strength of FRP composites consistently results in more conservativeness than the adoption of the Normal or the Lognormal distribution.

With the estimated lower bounds, the statistical uncertainty can be quantified by analyzing the ratio of $\widehat{x}_{0.05,0.75}$ to $\widehat{x}_{0.05}$, as listed in Table 5 . According to regression analysis, the average of the ratio of $\hat{x}_{0.05,0.75}$ to $\widehat{x}_{0.05}$ for the Normal, the Lognormal, and the Weibull distributions are 0.977, 0.979, and 0.971 with a corresponding c.o.v. of $0.011,0.010$, and 
0.013 , respectively. This means that, for purposes of simplicity, the characteristic value for structural design of the tensile strength of FRP composites based on the test results can be evaluated by

$$
\begin{aligned}
& \text { Normal: } \widehat{f}_{f k}=k_{f} \cdot \widehat{x}_{0.05}=0.977(\widehat{\mu}-1.645 \widehat{\sigma}), \\
& \text { Lognormal: } \left.\widehat{f}_{f k}=k_{f} \cdot \widehat{x}_{0.05}=0.979 \exp \left[\log \left(\frac{\widehat{\mu}^{2}}{\sqrt{\widehat{\sigma}^{2}+\widehat{\mu}^{2}}}\right)-1.645\right] \log \left(\frac{\widehat{\sigma}^{2}}{\widehat{\mu}^{2}+1}\right)\right] \\
& \text { Weibull: } \widehat{f}_{f k}=k_{f} \cdot \widehat{x}_{0.05}=0.971 \widehat{\alpha}[0.0513]^{1 / \beta}
\end{aligned}
$$

where the estimated parameters $\widehat{\mu}, \widehat{\sigma}, \widehat{\alpha}$, and $\widehat{\beta}$ can be determined according to equations (4)-(6) based on the tensile test results with respect to the specified distribution;.$k_{f}$ is a reduction factor that considers the uncertainty arising from parameter estimation. The reduction factors for the Normal, Lognormal, and Weibull distributions for all 58 collected datasets are shown in Figure 7.

\section{Conclusions}

In this work, a probabilistic model for the tensile strength of FRP composites is elaborated. After the construction of a relatively large experimental database, the Normal, the Lognormal, and the Weibull distributions were selected to fit the database using a tail-sensitive Anderson-Darling statistic as the measure of goodness of fit. Then, the probabilistic model considering statistical uncertainties for the tensile strength of FRP composites is proposed. According to the findings in this paper, the following conclusions can be drawn:

(1) From the perspective of experimental justification, all the Normal, the Lognormal, and the Weibull distributions can be used to model the tensile strength of FRP composites. From the perspective of theoretical justification, however, the Weibull distribution is recommended due to its intrinsic weakest link hypothesis of failure.

(2) Whether or not the statistical uncertainty is considered, the design values of FRP composites at the $5^{\text {th }}$ percentile obtained from the Normal and the Lognormal distributions are often larger than that from the Weibull distribution. In other words, the adoption of the Weibull distribution for design provides higher safety margins than the selection of the Normal or Lognormal distribution.

(3) When the experimental justification, the theoretical justification, as well as the design conservativeness are all taken into consideration, the Weibull distribution is the most recommended distribution to model the tensile strength of FRP composites.

(4) The proposed probabilistic model for the tensile strength of FRP composites considers the statistical uncertainties arising from parameter estimation. Such statistical uncertainties can be modeled by a reduction factor, and the design-oriented characteristic value is the product of the reduction factor and the estimated characteristic value. The reduction factor for the Weibull distribution is recommended to be 0.971 .

It should be noted that the provided reduction factor should be used with caution because it corresponds to the $5^{\text {th }}$ percentile lower bound with a 75\% confidence level. The reduction factors based on other specified percentiles and confidence levels should be evaluated and can be part of future work.

\section{Data Availability}

The data that support the findings of this study are available from the corresponding author upon reasonable request.

\section{Disclosure}

This manuscript was prepared and improved based on its earlier version as part of the thesis (https://biblio.ugent.be/ publication/8538031).

\section{Conflicts of Interest}

The authors declare that they have no conflicts of interest.

\section{Acknowledgments}

The authors would like to acknowledge the financial support from the Natural Science Foundation Program of Jiangsu Province (Grant no. BK20180393) and the National Natural Science Foundation of China (Grant no. 52008089) during the manuscript improvement.

\section{References}

[1] MIL-HDBK-17-1F composite materials Handbook, Polymer Matrix Composites Guidelines for Characterization of Structural Materials, US Department of Defense, Philadelphia, PA, USA, vol. 1, 2002.

[2] R. Atadero, L. Lee, and V. M. Karbhari, "Consideration of material variability in reliability analysis of FRP strengthened bridge decks," Composite Structures, vol. 70, no. 4, pp. 430-443, 2005. 
[3] A.-H. Zureick, R. M. Bennett, and B. R. Ellingwood, "Statistical characterization of fiber-reinforced polymer composite material properties for structural design," Journal of Structural Engineering, vol. 132, no. 8, pp. 1320-1327, 2006.

[4] E. Barbero, J. Fernández-Sáez, and C. Navarro, "Statistical analysis of the mechanical properties of composite materials," Composites Part B: Engineering, vol. 31, no. 5, pp. 375-381, 2000.

[5] M. Alqam, R. M. Bennett, and A.-H. Zureick, "Three-parameter vs. two-parameter Weibull distribution for pultruded composite material properties," Composite Structures, vol. 58, no. 4, pp. 497-503, 2002.

[6] M. A. Stephens, "EDF statistics for goodness of fit and some comparisons," Journal of the American Statistical Association, vol. 69, no. 347, pp. 730-737, 1974.

[7] S. Gomes, L. Neves, D. Dias-da-Costa, and E. Nuno Brito Santos Júlio, "Probabilistic models for mechanical properties of prefabricated CFRP," in Proceedings of the FRPRCS11 Symposium (Eds Joaquim Barros and José Sena-Cruz), pp. 1-8, Guimarães, Portugal, June 2013.

[8] P. P. Gohil and A. A. Shaikh, "Strength characterization of fibers and fibrous materials: experimental-reliability based novel approach," Materials and Design, vol. 51, pp. 105-112, 2003.

[9] K. Naresh, K. Shankar, R. Velmurugan, and N. K. Gupta, "Statistical analysis of the tensile strength of GFRP, CFRP and hybrid composites," Thin-Walled Structures, vol. 126, pp. 150-161, 2018.

[10] O. Ditlevsen, Uncertainty Modeling with Applications to Multidimensional Civil Engineering Systems, McGraw-Hill International Book Co., London, UK, 1981.

[11] Astm D3039/D 3039M, Standard Test Method for Tensile Properties of Polymer Matrix Composite Materials, ASTM, West Conshohocken, PA, USA, 2008.

[12] ISO Standard 2394, General Principles on Reliability for Structures, ISO, Geneva, Switzerland, 2015.

[13] Y. Ou and D. Zhu, "Tensile behavior of glass fiber reinforced composite at different strain rates and temperatures," Construction and Building Materials, vol. 96, pp. 648-656, 2015.

[14] B. W. Rosen, "Tensile failure of fibrous composites," AIAA Journal, vol. 2, no. 11, pp. 1985-1991, 1964.

[15] C. Zweben, "Tensile failure of fiber composites," AIAA Journal, vol. 6, no. 12, pp. 2325-2331, 1968.

[16] R. E. Bullock, "Strength ratios of composite materials in flexure and in tension," Journal of Composite Materials, vol. 8, no. 2, pp. 200-206, 1974.

[17] C. T. Sun and S. E. Yamada, "Strength distribution of a unidirectional fiber composite," Journal of Composite Materials, vol. 12, no. 2, pp. 169-176, 1978.

[18] J. M. Whitney and M. Knight, "The relationship between tensile strength and flexure strength in fiber-reinforced composites," Experimental Mechanics, vol. 20, no. 6, pp. 211-216, 1980.

[19] T. Shimokawa, Y. Hamaguchi, and H. Mitsuma, "Reliability evaluation of static and fatigue strengths of carbon/polyimide laminates," Science and Technology, vol. 87, pp. 91-96, 1990.

[20] I. J. Beyerlein and S. L. Phoenix, "Statistics for the strength and size effects of microcomposites with four carbon fibers in epoxy resin," Composites Science and Technology, vol. 56, no. 1, pp. 75-92, 1996.

[21] J. A. Lavoie, "Scaling effects on damage development, strength, and stress-rupture life on laminated composites in tension," Doctoral Dissertation, Virginia Tech, Blacksburg, VA, USA, 1997.
[22] M. K. Cattell and K. A. Kibble, "Determination of the relationship between strength and test method for glass fibre epoxy composite coupons using Weibull analysis," Materials \& Design, vol. 22, no. 4, pp. 245-250, 2001.

[23] R. O. Ochola, "Investigation of strain rate sensitivity of polymer matrix composites," Doctoral Dissertation, University of Cape Town, South Africa, ZA, 2004.

[24] B. Birgoren and M. Husnu Dirikolu, "A computer simulation for estimating lower bound fracture strength of composites using Weibull distribution," Composites Part B: Engineering, vol. 35, no. 3, pp. 263-266, 2004.

[25] G. Makarov, W. Wang, and R. A. Shenoi, "Deformation and fracture of unidirectional GFRP composites at High strain rate tension," COMP Test, vol. 2, pp. 527-534, 2004.

[26] M. M. Shokrieh and M. J. Omidi, "Tension behavior of unidirectional glass/epoxy composites under different strain rates," Composite Structures, vol. 88, no. 4, pp. 595-601, 2009.

[27] T. Okabe, K. Ishii, M. Nishikawa, and N. Takeda, "Prediction of tensile strength of unidirectional CFRP composites," Advanced Composite Materials, vol. 19, no. 3, pp. 229-241, 2010.

[28] W. Wang and W. Yang, "Statistical studies on material behavior of CFRP sheets under uniaxial loads and its application in reliability analysis," in Advances in FRP Composites in Civil Engineering, L. Ye, P. Feng, and Q. Yue, Eds., Springer, Berlin, Germany, pp. 61-64, 2011.

[29] B. Du, C. Ji, J. Chen, J. Guo, A. Sun, and X. Wei, "Study of tensile strength distribution based on composite materials for aeronautical Engineering," Modern Applied Science, vol. 6, no. 5, pp. 21-26, 2012.

[30] P. Sasikumar, R. Suresh, P. K. Vijayaghosh, and S. Gupta, "Experimental characterisation of random field models for CFRP composite panels," Composite Structures, vol. 120, pp. 451-471, 2015.

[31] Y. Ou, D. Zhu, H. Zhang et al., "Mechanical characterization of the tensile properties of glass fiber and its reinforced polymer (GFRP) composite under varying strain rates and temperatures,” Polymers, vol. 8, no. 5, p. 196, 2016.

[32] Y. Ma, Y. Yang, T. Sugahara, and H. Hamada, "A study on the failure behavior and mechanical properties of unidirectional fiber reinforced thermosetting and thermoplastic composites," Composites Part B: Engineering, vol. 99, pp. 162-172, 2016.

[33] Y. Ma, M. Ueda, T. Yokozeki, T. Sugahara, Y. Yang, and H. Hamada, "A comparative study of the mechanical properties and failure behavior of carbon fiber/epoxy and carbon fiber/polyamide 6 unidirectional composites," Composite Structures, vol. 160, pp. 89-99, 2017.

[34] L. Ascione, J. F. Caron, P. Godonou et al., "Prospect for new guidance in the design of FRP," EUR 27666 EN, Publications Office of the European Union, Ispra, Italy, 2016, https:// publications.jrc.ec.europa.eu/repository/handle/JRC99714.

[35] Fib Bulletin 14:, Externally Bonded FRP Reinforcement for RC Structure, International Federation for Structural Concrete (fib), Lausanne, Switzerland, 2002.

[36] EN 1990, Eurocode 0: Basis of Structural Design, European Committee for Standardization, Brussels, Belgium, 2002.

[37] L. Bain and M. Engelhardt, Statistical Analysis of Reliability and Life-Testing Models: Theory and Methods, Taylor \& Francis, London, UK, 2nd edition, 1991.

[38] L. J. Bain and M. Engelhardt, "Simple approximate distributional results for confidence and tolerance limits for the Weibull distribution based on maximum likelihood estimators," Technometrics, vol. 23, no. 1, pp. 15-20, 1981. 